\title{
Advanced abdominal pregnancy with dead foetus: a case report
}

\section{Mila Nu Nu Htay*, Nan Nitra Than, Htoo Htoo Kyaw Soe, Soe Moe, Adinegara Lutfi Abas}

Department of Community Medicine, Melaka Manipal Medical College (MMMC), Melaka, Malaysia

Received: 02 June 2017

Accepted: 29 June 2017

\section{*Correspondence: \\ Dr. Mila Nu Nu Htay, \\ E-mail: drmlnnh@gmail.com}

Copyright: () the author(s), publisher and licensee Medip Academy. This is an open-access article distributed under the terms of the Creative Commons Attribution Non-Commercial License, which permits unrestricted non-commercial use, distribution, and reproduction in any medium, provided the original work is properly cited.

\begin{abstract}
Abdominal pregnancy is a rare form of ectopic pregnancy in which the zygote implanted within the peritoneal cavity exception at ovaries, fallopian tubes and intra ligament spaces. The diagnosis is challenging and can be missed especially when the imaging facilities are not available in remote areas.

A 35 years old, $\mathrm{G}_{3} \mathrm{P}_{2+0}$ was admitted to the hospital at $38^{+2}$ weeks of pregnancy with the chief complaint of reduced foetal movement for three days. She was taking regular antenatal care with the midwife at the rural health centre and uneventful until 37 weeks of pregnancy. On physical examination, the abdomen was distended, the foetal parts were easily palpable, no visible foetal movement and the foetal heart sound was not audible. Abdominal ultrasound scan identified the term foetus of abdominal pregnancy without foetal cardiac activity. The patient underwent laparotomy and dead, male foetus was extracted uneventfully. The placenta was attached to intestines and mesentery so that which was removed with great caution and secured haemostasis. The mother's condition was stable throughout the operation and did not need to give the blood transfusion. The sutures were removed after 7 days and the healthy patient discharged from the hospital.

Abdominal pregnancy is a rare condition and the diagnosis can be missed during the antenatal period and hence it is crucial to raise the awareness of health care personals especially in remote areas. The suspicious case of abdominal pregnancy should be referred to the experienced clinicians in the centres with diagnosis facilities.
\end{abstract}

Keywords: Advanced abdominal pregnancy, Ectopic pregnancy, Extrauterine pregnancy

\section{INTRODUCTION}

Ectopic pregnancy is implantation of fertilized ovum outside the uterine cavity. ${ }^{1,2}$ Abdominal pregnancy is a rare form of ectopic pregnancy in which the zygote implanted within the abdominal cavity exception at ovaries, fallopian tubes and intra ligament spaces. ${ }^{3}$ The placenta implants on the surrounding structures commonly on intestines, omentum, mesentery, liver, spleen, uterus and the foetus can continue to grow with that blood supply. ${ }^{4}$

However, the chance of growing after 20 weeks of gestation is infrequent with the incidence of advanced abdominal pregnancy is 1 in 22,000 pregnancies. ${ }^{2,3}$ The complications of abdominal pregnancy are serious leaving high morbidity and mortality in both mother and foetus. The maternal mortality in case of abdominal pregnancy is $5.2 \%$, whereas the perinatal mortality is ranging between $40 \%$ to $95 \% .^{5-7}$

Although Ultrasound Scanning is the first line of imaging tool, it is usual to miss the diagnosis of abdominal pregnancy. ${ }^{8}$ Once the abdominal pregnancy is diagnosed, management is to remove the foetus from the abdominal cavity immediately to prevent the placenta separation and torrential haemorrhage. ${ }^{3}$

We reported a case of advanced abdominal pregnancy with dead foetus, which the diagnosis was missed during the antenatal period at remote area. 


\section{CASE REPORT}

A 35 years old, $\mathrm{G}_{3} \mathrm{P}_{2+0}$ was admitted to the hospital at $38^{+2}$ weeks of pregnancy with the chief complaint of reduced foetal movement for three days. She had no abdominal pain, no vaginal discharge and bleeding. According to the patient, she was taking regular antenatal care with the midwife at the rural health centre in her village, located at the central region of Myanmar. She was taking the iron supplement regularly and given antitetanus toxoid, two doses. However, the ultrasound scanning during the antenatal visits was not able to perform since the facility was lacking in that remote area. During the first and second trimester, she was well and uneventful. At 37 weeks of pregnancy, she noticed the remarkable reduction of foetal movement. Therefore, she went to the rural health centre and informed to the midwife. The midwife referred her to the tertiary hospital for further management. Her first two children were delivered normally at home with the midwife without any complications. She denies usage of any contraception methods. She had no significant past mensural, obstetric and gynaecological, medical and surgical history.

On physical examination, she was alert and well conscious. Her body weight was $73 \mathrm{~kg}$ and height was $165 \mathrm{~cm}$. She had mild pallor but no leg oedema. Her pulse rate was 98 per minute, blood pressure was $120 / 75$ and respiratory rate was 19 per minute. Cardiovascular and respiratory examinations of the women were normal. On abdominal examination, the abdomen was distended, the fetal parts were easily palpable, but no visible foetal movement. The uterus was palpable just below the level of umbilicus and firm in consistency. The foetal heart sound was not audible. On vaginal examination, the cervix was closed and directed posteriorly, no discharge and no bleeding.

Abdominal ultrasound scanning was done which revealed the term foetus of abdominal pregnancy without foetal cardiac activity. The uterus was detected with empty intrauterine cavity. The laboratory investigations of full blood count, coagulation profile, serum electrolytes, liver function test, renal function tests were within normal range except the presence of mild anemia, i.e., Haemoglobin 9.4 gm\%.

The next day, the laparotomy with the midline vertical incision was done under spinal anaesthesia. The dead full-term, male foetus was lying within the intact amniotic sac. The incision of the amniotic sac was made to deliver the dead foetus. The placenta was attached to intestines and mesentery so that which was removed with great caution to prevent the catastrophic bleeding. Some part of the placenta was firmly attached to the intestines and hence some parts were left with secured haemostasis. Peritoneal lavage was done by using normal saline and the drainage tube was inserted. The abdominal wall was sutured in layers. The mother's condition was stable throughout the operation and did not need to give the blood transfusion. Broad-spectrum antibiotic was given to prevent the infection and methotrexate was given for the resolution of the remnants of placenta tissues within the abdominal cavity. The sutures were removed after 7 days and the healthy patient discharged from the hospital.

\section{DISCUSSION}

In abdominal pregnancy, the zygote implanted within the peritoneal cavity exception at ovaries, fallopian tubes and intra ligament spaces. ${ }^{3}$ The placenta may implant to the nearby organs or structures and receive blood supply, which is necessary for the growth of the foetus within the abdominal cavity. ${ }^{4}$ In recent years, the advancement of assisted reproductive technologies (ARTs) and the increase in incidence of sexually transmitted diseases have impact on the increasing incidence of ectopic pregnancy. However, its impact on the incidence of abdominal pregnancy is yet to be explored. ${ }^{9,10}$

According to the site of implantation of the zygote, the abdominal pregnancy can be classified into two types, the primary and secondary types. The primary type, where the zygote directly implanted in the abdominal, is extremely rare compared to the secondary type. In secondary type, the zygote implanted in uterus, ovary or fallopian tube and then secondarily escaped to abdominal cavity. ${ }^{11}$ Depending on the gestational period at which they detected, the abdominal pregnancy can also be classified into early abdominal pregnancy, i.e., detected at or before 20 weeks of gestation, and advanced abdominal pregnancy, i.e., detected after 20 weeks of gestation. ${ }^{12}$ In this case, it was the advanced abdominal pregnancy identified after 38 weeks of pregnancy, which is a rarer condition compared to the early abdominal pregnancy.

The clinical signs and symptoms may be variable among the women with abdominal pregnancy. Based on the evidenced from the previous case reports and reviews, the common signs and symptoms which favour the suspicion of abdominal pregnancy are the persistent abdominal pain from 26 weeks onwards, persistent abnormal foetal lie, oligohydramnios, abnormally easy to palpate the foetal parts and abdominal mass palpated separately from the foetus. ${ }^{13}$ However, these finding may not be able to see in some abdominal pregnancies, like our case, where she denied any signs and symptoms except the reduced foetal movement.

As the clinical symptoms might be absence or variable, the ultrasound scan (USS) plays an important role to get the diagnosis of abdominal pregnancy. ${ }^{14}$ The availability and accessibility of the services are crucial to get the diagnosis especially in rural area. In this case, she has been taking regular antenatal care with the midwife at the villages, however, the radiographic facilities were lacking in that area. It might attribute to missing the early diagnosis in this pregnant woman in addition to the absence of clinical symptoms. 
High serum beta-hCG concentration, more than 2, 000 $\mathrm{iu} / \mathrm{L}$, in conjunction with the undetectable intra-uterine gestational sac in USS. ${ }^{15}$ Magnetic Resonance Imaging (MRI) is a useful tool to confirm the diagnosis of ectopic pregnancy. ${ }^{16}$ However, these facilities are rarely accessible in the remote area of the developing countries.

The management of abdominal pregnancy is surgical termination if detected early before 24 weeks of pregnancy to prevent the intra-abdominal haemorrhage. However, conservative management is still controversial for the advance abdominal pregnancy. ${ }^{11}$ The chance of survival of foetus in advance is low with perinatal mortality rate of $40-95 \% .{ }^{17}$ However, the infrequent case reports had been mentioned about the survival of term foetus in term abdominal pregnancies. ${ }^{13,18-20}$ In this woman, the abdominal pregnancy was uneventful and had progressive foetal movement until 37 weeks of pregnancy. After then, she noticed the reduction of foetal movements. If the diagnostic facilities were accessible, early diagnosis would have established and the foetus could have the chance of survival.

After delivery of the foetus, the placenta can be completely removed if the feeding vessel can be identified and ligation is feasible. ${ }^{21}$ If the haemostasis is not feasible, it is recommended to leave the placenta in situ to avoid the torrential bleeding. ${ }^{22}$ If the placenta is left in situ, methotrexate adjunctive therapy with the dosage of $1 \mathrm{mg} / \mathrm{kg}$ can be given to enhance the autolysis of the placental tissues. ${ }^{22}$ Adjunctive Methotrexate therapy was given to this case to enhance the resorption of placenta tissues.

\section{CONCLUSION}

Abdominal pregnancy is a rare condition in which the presenting symptoms and signs may vary or absent. The diagnosis can be missed during the antenatal period and hence it is crucial to raise the awareness of health care personals especially in remote areas. The suspicious case of abdominal pregnancy should be referred to the experienced clinicians in the centres with diagnosis facilities.

Funding: No funding sources

Conflict of interest: None declared

Ethical approval: Not required

\section{REFERENCES}

1. Daftary SN, Pai MV, Pralhad K, Sudip C. Ectopic Pregnancy. In: Holland and Brews Manual of Obstetrics. $4^{\text {th }}$ ed. Elsevier India; 2015:206-212

2. Nagamuthu E, Fatima S. Secondary abdominal pregnancy: a case report. Internat J Res Medic Sci. 2014;2(2):779-81.

3. Meena N, Khedia S, Rawat R. Secondary IntraAbdominal Pregnancy: A Case Report. Indian J Res. 2015;4(2):154-5.
4. Yildizhan R, Kolusari A, Adali F, Adali E, Kurdoglu $\mathrm{M}$, Ozgokce $\mathrm{C}$ et al. Primary abdominal ectopic pregnancy: a case report. Cases J. 2009;2(1):8485.

5. Jarry J, Peycru T, Tine I, Ougougbemy M, Diouf M. An ectopic abdominal pregnancy, rare cause of hemoperitoneum (article in French). Journal de Chirurgie Viscérale. 2010;147:148-9.

6. Faller E, Kauffmann E, Chevrière S, Heisert M, Ranjatoelina H, Boumahni B, et al. Full term abdominal pregnancy. J Gynecol Obstet Biol Reprod. 2006;35:732-5.

7. Randriambololona RA, Rakotovao M, Rakototiana AF, Botolahy ZA, Rakoto- Ratsimba HN. Spontaneous evisceration of an abdominal pregnancy: report of a case in Madagascar. Gynecologie Obstetrique and Fertilité. 2011;39:e4-6.

8. Amal A Dahab, Rahma Aburass, Wasima Shawkat, Reem Babgi, Ola Essa and Razaz H Mujallid. Fullterm extrauterine abdominal pregnancy: a case report. J Med Case Reports. 2011;5:531.

9. Voedisch AJ, Frederick CE, Nicosia AF, Stovall TG. Early pregnancy loss and ectopic pregnancy. In: J.S. Berek, E. Novak (Eds.) Berek and Novak's Gynecology. 15th ed. Wolters Kluwer Health and Lippincott Williams \& Wilkins, Philadelphia, PA. 2012:619-51.

10. Koyama S, Yoshino A, Okuno K, Naoi H, Watanabe $\mathrm{M}$, Ozaki $\mathrm{K}$ et al. A case of abdominal pregnancy following in vitro fertilization and embryo transfer treated with laparoscopic surgery. Gynecol Minimally Invasive Therapy. 2016;5(3):132-3.

11. Okafor I, Ude A, Aderibigbe A, Amu O, Udeh P, Obianyo N, et al. Abdominal Pregnancy - A Case Report. J West Afr Coll Surg. 2011;1(1):121-30.

12. Agarwal N, Odejinmi F. Early abdominal ectopic pregnancy: challenges, update and review of current management. Obstet Gynaecol. 2014;16(3):193-8.

13. Yusuf N, Nahar N, Begum M, Nigar T. Advanced abdominal pregnancy with alive fetus: A case report and review. The ORION Medic J. 2010;33(1):733-4.

14. Dahab A, Aburass R, Shawkat W, Babgi R, Essa O, Mujallid R. Full-term extrauterine abdominal pregnancy: a case report. J Medic Case Reports. 2011;5(1):531.

15. Oriaifo $\mathrm{N}$, Njoku A, Oriaifo $\mathrm{S}$, Oriaifo $\mathrm{M}$. Adjunctive use of methotrexate in the management of advanced abdominal pregnancy: a case report and literature review. Int Res J Pharm Pharmacol. 2014;4(2):18-21.

16. Yoshigi J, Yashiro N, Kinoshito T, O'uchi T, Kitagaki H. Diagnosis of ectopic pregnancy with MRI: efficacy of T2-weighted imaging. Magn Reson Med Sci. 2006;5:25-32

17. Martin JN, Sessums JK, Martin RW, Pryor JA, Morrison JC. Abdominal pregnancy: current concepts of management. Obstet Gynecol. 1988;71(4):549-57.

18. Baffoe P, Fofie C, Gandau BN. Term Abdominal Pregnancy with Healthy Newborn: A Case Report. Ghana Medic J. 2011;45(2):81-3. 
19. Abeda K, Laila A. Term alive intra-abdominal ectopic pregnancy. Bangladesh J Med Sci. 2012;11(1):68-70.

20. Mutarambirwa H, Kenfack B, Fouogue J. Term Abdominal Pregnancy Revealed by Amnioperitoneum in Rural Area. Case Reports Obstet Gynecol. 2017;2017:1-4.

21. Hallat JG, Grove JA. Abdominal pregnancy: a study of twenty one consecutive cases. Am J Obstet Gynecol. 1985;152:444-9.
22. Oriaifo N, Njoku AI, Oriaifo SE, Oriaifo MO. Adjunctive use of methotrexate in the management of advanced abdominal pregnancy: a case report and literature review. Int Res J Pharm Pharmacol. 2014;4(2):18-21.

Cite this article as: Htay MNN, Than NN, Soe HHK, Moe S, Abas AL. Advanced abdominal pregnancy with dead foetus: a case report. Int J Reprod Contracept Obstet Gynecol 2017;6:3660-3. 